\title{
Optimal Usage of Meropenem Based on Recommended Regimen Derived from Monte Carlo Simulation
}

\author{
Takahiro Muro*12, Shinsuke Takemoto ${ }^{1}$, \\ Hidetoshi Kamimura ${ }^{2}$ and Yoshiharu Karube ${ }^{2}$ \\ Department of Pharmacy, Iizuka Hospital ${ }^{1}$ \\ Pharmaceutical Sciences, Fukuoka University Graduate School ${ }^{2}$ \\ Received September 13, 2007
}

\begin{abstract}
Long-term treatment with antibacterial agents is thought to be a cause of increased susceptibility to resistance. To prevent resistance in bacteria, a method of determining adequate regimens is needed and the Monte Carlo simulation (MCS) has proved useful for this purpose. In order to evaluate the inhibitory effect of the meropenem (MEPM) usage amount according to the recommended regimen based on the results of the MCS, we conducted a retrospective study using data from a database of inpatients at lizuka hospital in 2006. We estimated the usefulness of the recommended regimen by comparing MEPM daily doses and the integrated frequency rate (IFR) of the percentage time it was above the MIC ( \% T > MIC) with those of the actual regimens. The results of doing this indicated that switching the actual regimens to MCS results based regimens would have decreased the daily dose of MEPM by $43.9 \%$. We also found that for the same dosing interval and daily dose, a regimen with a shorter infusion time achieved a higher IFR for \% T > MIC values of $30 \%$ and $50 \%$. This finding serves as a caution that just selecting a prolonged infusion time is not certain to raise the IFR of \%T $>$ MIC. Thus, the selection of appropriate dosages in consideration of the MIC of the pathogen and achieving high IFR levels will provide accurate and effective administration of MEPM
\end{abstract}

Key words — Monte Carlo simulation, meropenem, daily dose, time above the MIC, decrease consumption

\section{Introduction}

Meropenem (MEPM) belongs to the carbapenem group of antibacterial agents with a broad spectrum and high antimicrobial activity ${ }^{1}$. Therefore MEPM is used as a first-line antibiotic against hospital-acquired pneumonia ${ }^{2}$ and many other infectious diseases defined in a number of guidelines $^{3,4}$. Carbapenems constitute one of the most active groups of betalactams against $P$. aeruginosa and, are frequently employed as an empirical treatment of serious infections that may be caused by $P$. aeruginos $a^{11}$. However, drugresistant microorganisms have become a major problem all over the world and there are carbapenem resistant $P$. aeruginosa strains. Furthermore, nosocomial infections caused by multiple-drug-resistant strains of $P$. aeruginosa (MDRP) have become a severe problem throughout Japan ${ }^{5,6)}$. Meropnem has high antimicrobial activity against $P$. aeruginosa. Nevertheless, $P$. aeruginosa rapidly developed resis tance to many antibacterial agents, via diverse and complex mechanisms $^{6-11)}$. Long-term treatment with antibacterial agents is regarded as one of the causes of the increased sus ceptibility to resistance ${ }^{12)}$. Thus, a number of trials to inhibit antibiotic use and to develop other methods of preventing resistance are being conducted ${ }^{13-19}$. The theories of pharma cokinetics and pharmacodynamics have been brought together to design an optimized evidence-based regimen. The relationship between the antimicrobial effect and the concentration of antibiotics has previously been established ${ }^{20)}$. In animal studies using carbapenems such as MEPM, bacte riostatic and bactericidal responses were observed when drug concentrations remained above their minimum inhibitory concentration (MIC) for approximately $20 \%$ to $30 \%$, and 40 $\%$ to $50 \%$, respectively, of the dosing interval ${ }^{18,21,22)}$. This ratio of the time when drug concentrations exceeds MIC all over the dosing interval is called the percentage of the time above the MIC (\%T > MIC). For the last few years, the Monte Carlo simulation (MCS) has been used as an acceptable method of evaluating the probability of experimental dosage regimens in attaining pre-specified pharmacodynamic target attainments against specific pathogens ${ }^{23-31)}$.The output of these simulations represents the likelihood of a drug regimen achieving a defined exposure against these microorganisms, such as the \% $>$ MIC required for a bacteriostatic or bactericidal effect ${ }^{311}$. Concretely, this simulation uses the pharmacokinetic data of antibiotics, the frequency rate of the 
MIC of a specific bacterial species, experimental dosage regimens and a calculating equation of the $\% \mathrm{~T}>\mathrm{MIC}$. Then the results are obtained as the integrated frequency rate (IFR) at the \% T > MIC of each value.

Earlier, we showed that a therapeutic drug monitoring (TDM) system reduced the amount and duration of pre scribed anti-methicillin-resistant Staphylococcus aureus (MRSA) agents and considered that a similarly operated TDM system for anti-MRSA agents is necessary to ascertain the adequate regimens for carbapenems ${ }^{19)}$. Then we considered that the MCS is a useful method for this purpose, to decrease the dosage of carbapenems.

Thus, to evaluate the inhibition effect on the dosage of carbapenems of using recommended regimens according to the results of MCS, we conducted a retrospective study us ing a database of inpatients.

\section{Patients and methods}

This study was conduced as follows:

1. A survey of actual regimens was used to estimate the IFR of \%T > MIC

2. A comparison of the IFR of $\% \mathrm{~T}>\mathrm{MIC}$ was made among several regimens to find regimens that show higher IFR than actual regimens

3. A comparison of daily doses was made to estimate the inhibiting effect of recommended regimen use according to the results of the MCS

\section{Parameters used in the MCS}

Pharmacokinetics and Renal function groups

Pharmacokinetic data of MEPM were obtained from literature of Japanese health volunteers and patients with various degrees of renal impairment. Degrees of renal function were categorized into four groups (Table $\mathbf{1} \mathbf{A})^{32,33)}$.

\section{Target microorganism}

Bearing in mind the object of preventing drug resistance, the antibiotics dose regimen needs to be established focusing on bacteria with the highest MIC for administered antibiotics in causative pathogens against infectious diseases. Thus, $P$. aeruginosa was selected.

\section{MIC values}

MIC values of MEPM against P.aeruginosa and their fre quencies were derived from our database of 852 samples taken from clinical patients at lizuka hospital between January 2005 and December 2006.

MIC values were measured by VITEK ${ }^{\circledR}$ 2(manufactured by bioMrerieux INDUSTRY) and assigned by category to one of the following: $\leq 0.25,0.5,1,2,4,8$, and $\geq 14 \mathrm{~g} /$ $\mathrm{mL}$. We categorized MIC values into eight ranges to calculate by Monte Carlo simulation : 0.06 to $0.25,0.25$ to 0.50 , 0.5 to 1,1 to 2,2 to 4,4 to 8,8 to 16 , and 16 to $254 \mathrm{~g}$ / $\mathrm{mL}$. A minimum value was defined according to surveillance data available in Japan. Twice the value of the de tected maximum MIC range according to the same surveillance data $(\geq 128)$ was defined as a maximum value (Table $1 \mathbf{B})^{1)}$.

\section{Calculation of the IFR of $\% T>M I C$}

The IFR of \% T > MIC in each renal function group was calculated using a 10,000-subject MCS on Crystal Ball 7 professional (Decisioneering Inc.).

A ccording to the literature ${ }^{28)}$, a one-compartment equation that combined an intravenous infusion during the distribution phase of the concentration-time curve and an intrave nous bolus during the elimination phase was used :

$$
\% \mathrm{~T}>\mathrm{MIC}=\left(\mathrm { t } _ { \mathrm { inf } } \left(\operatorname { l n } ( ( \mathrm { Ro } / \mathrm { CL } ) / ( \mathrm { Ro } / \mathrm { CL } - \mathrm { MIC } ) ) ^ { * } \left(\mathrm{t}_{1 / 2} /\right.\right.\right.
$$$$
\left.0.693)))+\left((\operatorname{In}(\mathrm{Ro} / \mathrm{CL})-\operatorname{In}(\mathrm{MIC}))^{*}\left(\mathrm{t}_{1 / 2} / 0.693\right)\right)\right)^{*}(100 / \mathrm{DI})
$$

(Equation 1)

$\mathrm{t}_{\text {inf }}$ : infusion time, Ro : infusion rate in $\mathrm{mg} / \mathrm{h}, \mathrm{CL}$ : clearance, MIC : minimum inhibitory concentration, $t_{1 / 2}$ : half-life, DI : dose interval

In simulation, distributions of $C L$ and $t_{1 / 2}$ were assumed the log normality distribution. The MIC values were defined as distribute with constant probability in continuous ranges and applied the custom distribution on Crystal Ball 7 profes sional. Those continuous ranges were applied eight ranges above. Those probabilities were obtained from actual detective rates.

\section{The survey of actual regimens used in Iizuka hospital in 2006}

From actual regimens obtained from 714 adult patients prescribed MEPM at lizuka hospital in 2006, regimens of 299 adult patients in whom we were able to estimate the $\mathrm{CL}_{\mathrm{CR}}$ were selected to conduct the comparison study. The $\mathrm{CL}_{\mathrm{CR}}$ of patients were calculated using the Cockcroft-Gault equation. Degrees of renal function were categorized into the same four groups as above. According to several re ports $\left.{ }^{18} 2122\right)$, the bacteriostatic and the bactericidal exposure $\% \mathrm{~T}>\mathrm{MICs}$ were defined as 30 and 50 , respectively. The IFRs at the \%T > MIC values of 30 and 50 of patients were extrapolated the results of the MCS. Then, the average IFR and the number of patients who achieved the target attainment rate of over $80 \%$ and over $90 \%$ were calculated at the $\% \mathrm{~T}>$ MIC values of 30 and 50 . In addition, the totals of daily doses were calculated in each renal function group.

\section{Finding regimens that show higher IFR than actual regimens \\ Regimens}

Regimens were selected by combining the following :

Dosage : 250, 500 and $1000 \mathrm{mg}$

Dose interval : 48, 24, 12, 8, 6 and $3 \mathrm{~h}$

Infusion time : 0.5, 1 and $3 \mathrm{~h}$

The daily dose was accommodated within 250 to 2000 $\mathrm{mg}$ according to the instructions printed on the package insert in Japan ${ }^{34}$. Therefore, for the renal function group cre atinine clearance $\left(C L_{C R}\right)<70 \mathrm{~mL} / \mathrm{min}$, we adopted limited 
Table 1. Summary of Parameters Used in the Monte Carlo Simulation

A. Pharmacokinetics parameters andd variability for meropenem

Pharmacokinetic parameter, mean (S.D.)

Dose (mg) Renal function ( $\mathrm{mL} / \mathrm{min}) \quad \mathrm{t}_{1 / 2}(\mathrm{~h}) \quad \mathrm{CL}(\mathrm{L} / \mathrm{h})$

\begin{tabular}{cccc}
\hline 250 & $\mathrm{CL}_{\mathrm{CR}} \geq 70$ & $0.98(0.20)^{\mathrm{a}}$ & $16.27(4.50)^{\mathrm{a}}$ \\
500 & $\mathrm{CL}_{\mathrm{CR}} \geq 70$ & $1.03(0.13)^{\mathrm{a}}$ & $14.88(1.54)^{\mathrm{a}}$ \\
500 & $50 \leq \mathrm{CL}_{\mathrm{CR}}<70$ & $1.54(0.70)^{\mathrm{b}}$ & $14.60(3.90)^{\mathrm{b}}$ \\
500 & $30 \leq \mathrm{CL}_{\mathrm{CR}}<50$ & $3.36(1.02)^{\mathrm{b}}$ & $7.70(3.00)^{\mathrm{b}}$ \\
500 & $\mathrm{CL}_{\mathrm{CR}}<30$ & $5.00(1.05)^{\mathrm{b}}$ & $3.00(1.00)^{\mathrm{b}}$ \\
1000 & $\mathrm{CL}_{\mathrm{CR}} \geq 70$ & $1.02(0.12)^{\mathrm{a}}$ & $17.46(2.17)^{\mathrm{a}}$ \\
\hline
\end{tabular}

$\mathrm{CL}_{\mathrm{CR}}:$ creatinine clearance, $\mathrm{t}_{1 / 2}:$ half-life, $\mathrm{CL}:$ clearance

a. $\mathrm{t}_{1 / 2}$ and $\mathrm{CL}$ data of group of $70 \mathrm{~mL} / \mathrm{min}<\mathrm{CL}_{\mathrm{CR}}$ adapted from Mitsuyoshi Nakashima et al

b. $\mathrm{t}_{1 / 2}$ and $\mathrm{CL}$ data of group of $\mathrm{CL}_{\mathrm{CR}}<70 \mathrm{~mL} / \mathrm{min}$ adapted from Minoru Chimata et $\mathrm{a}^{33}$ )

B. Frequency distributions of the MIC values of meropenem against P.aeruginosa

\begin{tabular}{|c|c|c|c|}
\hline \multicolumn{2}{|c|}{ Range of MICs $(\mu \mathrm{g} / \mathrm{mL})$} & \multirow[b]{2}{*}{$n$} & \multirow[b]{2}{*}{ Frequency $(\%)$} \\
\hline Minimum & Maximum & & \\
\hline 0.06 & 0.25 & 432 & 50.7 \\
\hline 0.25 & 0.50 & 3 & 0.4 \\
\hline 0.50 & 1.00 & 62 & 7.3 \\
\hline 1.00 & 2.00 & 100 & 11.7 \\
\hline 2.00 & 4.00 & 28 & 3.3 \\
\hline 4.00 & 8.00 & 89 & 10.4 \\
\hline 8.00 & 16.00 & 73 & 8.6 \\
\hline 16.00 & 256.00 & 65 & 7.6 \\
\hline
\end{tabular}

MIC values of MEPM against P.aeruginosa and their frequencies were derived from our data base of 852 samples taken from clinical patients at lizuka hospital between January 2005 and December 2006.

MIC values were measured by VITEK ${ }^{\circledR} 2$ (manufactured by bioMerieux INDUSTRY).

We categorized MIC values into eight ranges to calculate by Monte Carlo simulation. Range of MICs was defined according to surveillance data in Japan. ${ }^{1)}$

MICs : minimum inhibitory concentrations

regimen : $500 \mathrm{mg}$ for the dose, because we did not obtain the pharmacokinetic parameters for other amounts (Table 1 A).

Comparison of the IFR of the \% T>MIC among dose regimens on daily doses at each renal function group

The class frequencies at each point at 5 intervals between 0 and 100 of $\% \mathrm{~T}>\mathrm{MIC}$ s were calculated from results of the MCS. They were then divided into the group achieving the bacteriostatic exposure \% T > MIC and other groups in each dose regimen. In addition, they were divided into groups achieving the bactericidal exposure of the \% $>$ MICs and others on each dose regimen. Using the above divided class frequencies, in each renal function group the Chi square test was used to compare the achievement rate at the \% $>$ MIC values of 30 and 50 among dose regimens of several daily doses in each renal function group. 
Comparison of the IFR of $\% T>M I C$ among daily dose in several renal impairment groups

Regimens achieving the highest attainment rate at both the bacteriostatic and the bactericidal of the \% $\mathrm{T}>\mathrm{MIC}$ in each daily dose were selected. Then, the Chi square test was used to compare these achievement rates among daily doses on each renal function group by the above method.

$\mathrm{P}<0.01$ was deemed significant for all tests.

\section{Estimating the inhibiting effect of recommended regi-} men use according to the results of the MCS

Definition of the alternate regimens and improved regimens

In regimens simulated by the MCS in each renal function group, those achieving the closest IFRs to the average IFR of the actual regimens using the smallest daily dose were defined as alternate regimens.

Next, from the results of the survey of actual regimens used, the daily dose of each renal function group was obtained and averages of daily doses were calculated. Then, in simulated regimens in each renal function group, those achieving the highest IFR by using less than the average daily doses of actual regimens were defined as improved regimens.

Comparison of daily doses and comparison of the IFR at the $\% T>M I C$ values of 30 and 50

First, in each renal function group, the totals of daily doses of actual regimens used were compared to the totals of daily doses of hypothetical use in alternate regimens. Next, in each renal function group, the average IFR at the $\% \mathrm{~T}>$ MIC values of 30 and 50 of actual regimens used were compared to the IFRs of hypothetical use in improved regimens. Then the two-tailed Mann-Whitney U-test was used to compare. $\mathrm{P}<0.01$ was deemed significant.

\section{Results}

MIC values of MEPM against P.aeruginosa and their rates of frequencies (Table $1 \mathrm{~B}$ ) showed that $50.7 \%$ of samples were categorized in $\mathrm{MIC} \leq 0.25 \mathrm{~g} / \mathrm{mL}$ and $7.6 \%$ of samples were categorized in $\mathrm{MIC} \geq 19 \mathrm{~g} / \mathrm{mL}$.

A summary of actual dose regimens of the 299 adult pa tients in whom we were able to calculate the $\% \mathrm{~T}>\mathrm{MIC}$ is shown in Table 2. The IFR average was $85.2 \%$ at the $\% \mathrm{~T}$ $>$ MIC value of 30 and $74.9 \%$ at the $\% \mathrm{~T}>$ MIC value of 50. However, the percentage of patients whose IFR was over $80 \%$ was $68.2 \%$ at the $\% \mathrm{~T}>\mathrm{MIC}$ value of 30 and $44.1 \%$ at the $\% \mathrm{~T}>\mathrm{MIC}$ value of 50 . In addition, the number of patients whose IFR was over $90 \%$ was less than $50 \%$ at the $\% \mathrm{~T}>$ MIC values of 30 and 50. Patients who had lower $\mathrm{CL}_{\mathrm{CR}}$ had a higher IFR and a higher target attainment rate at the \% T > MIC values of 30 and 50 .

Table 3 is the list of regimens that show higher IFR of \% $\mathrm{T}>\mathrm{MIC}$ than actual regimens and shows the results of comparing the IFR of \% T > MIC among dose regimens in each daily dose in each renal function group. With the same daily dose, the regimen of a shorter dose interval achieved a higher IFR at both targets of \% $>$ MIC values of 30 and 50. In addition, with the same dose interval and daily dose, the regimen of shorter infusion time achieved a higher IFR at the $\% \mathrm{~T}>\mathrm{MIC}$ values of 30 and 50 . Most dose regimens with the same daily dose showed a significant difference. The pair in which significant difference was not recognized was defined as coordinate. The regimens of a higher daily dose achieved a higher IFR at the \% T > MIC values of 30 and 50. However, some assortments showed no significant difference.

Table 4 shows the results of comparing the daily dose of the actual regimens and the alternate regimens. A lternated regimens enabled the daily dose to be decreased by $43.9 \%$. The improved regimens were defined as regimens achieving the highest IFR by using less than the average daily dose of the actual regimens. The results of comparing the IFR of \% $\mathrm{T}>\mathrm{MIC}$ between the actual regimens and the improved regimens is shown in Table 4 . At $\% \mathrm{~T}>\mathrm{MIC}=30$, for all re nal function groups, improved regimens increased the IFR significantly. Furthermore, at $\% \mathrm{~T}>\mathrm{MIC}=50$, in total of pa tients, improved regimens increased the IFR significantly. In the renal function groups, in only one group : $\mathrm{CL}_{\mathrm{CR}} \geq 70 \mathrm{~mL}$ /min, did the IFR show a significant increase. However, for the other renal function groups, the IFR increased.

\section{Discussion}

The purpose of this study was to simulate the optimal us age of MEPM by recommended regimen defined by the MCS. The results of this study indicate that using recommended regimens based on results of MCS contribute to a decrease in the consumption of MEPM.

Our study had two major findings. First, the results show that following the Japanese recommended dose from the instructions, the blind choice of the prolonged infusion causes the IFR of $\% \mathrm{~T}>\mathrm{MIC}$ rise to be uncertain. With the same dose interval and the same daily dose, the regimen of shorter infusion time achieved a higher IFR at the \% $>$ MIC values of 30 and 50 . This finding is in disharmony with divers reports ${ }^{18,28,35,36,37}$. In general, the regimen of rapid infusion speed such as bolus injection achieves a higher maximum drug concentration than the regimen of slow infusion speed such as continuous infusion. This is because even during infusion, the drug concentration is decreasing according to its half-life. In addition, the regimen of slower infusion speed has a longer maximum drug concentration time ${ }^{35}$. Therefore, if the MIC of the target pathogen is high, there is a possibility that the regimen of slow infusion speed cannot raise the drug concentration above the MIC of the target pathogen. To keep the time above the MIC, the high dose or the short interval is required ${ }^{35}$. Concerning MEPM, the halflife is 0.98 to 1.03 hours in the renal function groups: $C L_{C R}$ $\geq 70 \mathrm{~mL} / \mathrm{min}$ and one of the shortest half-lives in beta Iactams ${ }^{4}$. Therefore, its blood concentration is relative to the infusion speed. Mikamo reported in his study that MEPM 
Table 2. Summary of actual dose regimens of 299 adult patients prescribed meropenem : patients in whom we were able to calculate the $\%$ T > MIC

\begin{tabular}{|c|c|c|c|c|c|c|c|c|}
\hline \multirow[t]{2}{*}{ Renal function (mL/min) } & & \multicolumn{3}{|c|}{ Dose regimens } & \multirow[t]{2}{*}{$n$} & \multirow[t]{2}{*}{ Frequency $(\%)$} & \multicolumn{2}{|c|}{ IFR(\%)at each target of the $\% \mathrm{~T}>\mathrm{MIC}$} \\
\hline & & Dose (mg) & Dose interval (h) & Infusion time (h) & & & $\% \mathrm{~T}>\mathrm{MIC}=30$ & $\% \mathrm{~T}>\mathrm{MIC}=50$ \\
\hline \multirow[t]{12}{*}{$\mathrm{CL}_{\mathrm{CR}}<30$} & & 500 & 8 & 1 & 6 & 2.0 & 95.7 & 95.2 \\
\hline & & & & 0.5 & 1 & 0.3 & 98.6 & 97.9 \\
\hline & & & 12 & 1 & 37 & 12.4 & 95.3 & 94.5 \\
\hline & & & & 0.5 & 4 & 1.3 & 98.0 & 96.6 \\
\hline & & & 24 & 1 & 38 & 12.7 & 94.0 & 92.9 \\
\hline & & & & 0.5 & 4 & 1.3 & 95.9 & 94.3 \\
\hline & & & 48 & 0.5 & 1 & 0.3 & 93.5 & 86.1 \\
\hline & IFR average* & & & & & & $95.0 \pm 1.0$ & $93.9 \pm 1.4$ \\
\hline & Number of patients (rate) & & & & & & & \\
\hline & total & & & & 91 & & & \\
\hline & IFR $>90 \%$ & & & & & & $91(100.0 \%)$ & $90(98.9 \%)$ \\
\hline & IFR $>80 \%$ & & & & & & $91(100.0 \%)$ & $91(100.0 \%)$ \\
\hline \multirow[t]{11}{*}{$30 \leq \mathrm{CL}_{\mathrm{CR}}<50$} & & 500 & 8 & 2 & 1 & 0.3 & 91.4 & 88.9 \\
\hline & & & & 1 & 10 & 3.3 & 93.4 & 92.8 \\
\hline & & & & 0.5 & 1 & 0.3 & 94.5 & 93.7 \\
\hline & & & 12 & 1 & 19 & 6.4 & 93.0 & 90.8 \\
\hline & & & & 0.5 & 4 & 1.3 & 93.8 & 92.6 \\
\hline & & & 24 & 1 & 4 & 1.3 & 88.7 & 77.6 \\
\hline & IFR average* & & & & & & $92.7 \pm 1.4$ & $90.2+4.4$ \\
\hline & Number of patients (rate) & & & & & & & \\
\hline & total & & & & 39 & & & \\
\hline & IFR $>90 \%$ & & & & & & $35(89.7 \%)$ & $34(87.2 \%)$ \\
\hline & IFR > 80\% & & & & & & $39(100.0 \%)$ & $35(89.7 \%)$ \\
\hline \multirow[t]{11}{*}{$50 \leq \mathrm{CL}_{\mathrm{CR}}<70$} & & 500 & 8 & 2 & 1 & 0.3 & 77.6 & 67.7 \\
\hline & & & & 1 & 9 & 3.0 & 85.0 & 75.0 \\
\hline & & & & 0.5 & 2 & 0.7 & 90.5 & 83.1 \\
\hline & & & 12 & 1 & 16 & 5.4 & 77.8 & 62.6 \\
\hline & & & & 0.5 & 4 & 1.3 & 85.4 & 70.6 \\
\hline & & & 24 & 1 & 1 & 0.3 & 54.9 & 25.5 \\
\hline & IFR average* & & & & & & $80.7 \pm 6.2$ & $67.2+9.8$ \\
\hline & Number of patients (rate) & & & & & & & \\
\hline & total & & & & 33 & & & \\
\hline & IFR $>90 \%$ & & & & & & $2(6.1 \%)$ & $O(0.0 \%)$ \\
\hline & IFR $>80 \%$ & & & & & & $15(45.5 \%)$ & $2(6.1 \%)$ \\
\hline \multirow[t]{22}{*}{$\mathrm{CL}_{\mathrm{CR}} \geq 70$} & & 500 & 8 & 1 & 25 & 8.4 & 80.7 & 68.8 \\
\hline & & & 12 & 2 & 1 & 0.3 & 65.8 & 47.1 \\
\hline & & & & 1 & 33 & 11.0 & 71.7 & 53.1 \\
\hline & & & & 0.5 & 4 & 1.3 & 79.1 & 61.0 \\
\hline & & & 24 & 1 & 3 & 1.0 & 42.7 & 0.3 \\
\hline & & 1000 & 8 & 1 & 20 & 6.7 & 87.8 & 73.6 \\
\hline & & & & 0.5 & 4 & 1.3 & 92.1 & 82.2 \\
\hline & & & 12 & 2 & 1 & 0.3 & 71.0 & 52.3 \\
\hline & & & & 1 & 31 & 10.4 & 77.0 & 59.1 \\
\hline & & & & 0.5 & 10 & 3.3 & 85.7 & 67.2 \\
\hline & & & 24 & 1 & 2 & 0.7 & 50.8 & 0.9 \\
\hline & & & & 0.5 & 2 & 0.7 & 57.6 & 3.8 \\
\hline & IFR average* & & & & & & $77.6 \pm 9.0$ & $59.8 \pm 15.8$ \\
\hline & Number of patients (rate) & & & & & & & \\
\hline & total & & & & 136 & & & \\
\hline & IFR $>90 \%$ & & & & & & $4(2.9 \%)$ & $O(0.0 \%)$ \\
\hline & $\mathrm{IFR}>80 \%$ & & & & & & $59(43.4 \%)$ & $4(2.9 \%)$ \\
\hline & IFR average* & & & & & & $85.2+10.3$ & $74.9 \pm 19.4$ \\
\hline & Number of patients (rate) & & & & & & & \\
\hline & total & & & & 299 & & & \\
\hline & IFR $>90 \%$ & & & & & & $132(44.1 \%)$ & $124(41.5 \%)$ \\
\hline & IFR $>80 \%$ & & & & & & $204(68.2 \%)$ & $132(44.1 \%)$ \\
\hline
\end{tabular}

The creatinine clearance of patiens were calculated using the Cockcroft-Gault equation.

The integrated frequency rate (IFR) of the \% T > MIC values of 30 and 50 of patients were extrapolated the results of the Monte Carlo simulation on same renal function group and same regimens as actual. 
Table 3. The list of regimens that show higher IFR of \% $>$ MIC than actual regimens

\begin{tabular}{|c|c|c|c|c|c|c|c|c|c|c|c|c|}
\hline \multirow[t]{3}{*}{ Renal function (mL/min) } & \multirow{2}{*}{\multicolumn{4}{|c|}{ Dose regimens }} & \multicolumn{8}{|c|}{ Target of the $\% \mathrm{~T}>\mathrm{MIC}$} \\
\hline & & & & & \multicolumn{4}{|c|}{$\% \mathrm{~T}>\mathrm{MIC}=30$} & \multicolumn{4}{|c|}{$\% \mathrm{~T}>\mathrm{MIC}=50$} \\
\hline & $\begin{array}{c}\text { Daily } \\
\text { dose(mg) }\end{array}$ & Dose(mg) & $\begin{array}{c}\text { Dose } \\
\text { interval }(\mathrm{h})\end{array}$ & $\begin{array}{l}\text { Infusion } \\
\text { time(h) }\end{array}$ & IFR( \%) & Ranking $1^{\text {a) }}$ & Ranking $2^{\mathrm{b})}$ & Markc) & IFR( \%) & Ranking 1 & Ranking $2^{b)}$ & Mark ${ }^{c)}$ \\
\hline \multirow[t]{7}{*}{$\mathrm{CL}_{\mathrm{CR}}<30$} & 500 & 500 & 24 & 0.5 & 95.9 & 1 & 4 & $A \& I$ & 94.3 & 1 & 4 & A \& I \\
\hline & 1000 & 500 & 12 & 0.5 & 98.0 & 1 & 3 & & 96.6 & 1 & 3 & \\
\hline & & 500 & 12 & 1 & 95.3 & 2 & & & 94.5 & 2 & & \\
\hline & 1500 & 500 & 8 & 0.5 & 98.6 & 1 & 2 & & 97.9 & 1 & 2 & \\
\hline & & 500 & 8 & 1 & 95.7 & 2 & & & 95.2 & 2 & & \\
\hline & 2000 & 500 & 6 & 0.5 & 99.0 & 1 & 1 & & 98.4 & 1 & 1 & \\
\hline & & 500 & 6 & 1 & 96.0 & 2 & & & 95.5 & 2 & & \\
\hline \multirow{6}{*}{$30 \leq \mathrm{CL}_{\mathrm{CR}}<50$} & 1000 & 500 & 12 & 0.5 & 93.8 & 1 & 1 & 1 & 92.6 & 1 & 2 & I \\
\hline & & 500 & 12 & 1 & 93.0 & 2 & & A & 90.8 & 2 & & A \\
\hline & 1500 & 500 & 8 & 0.5 & 94.5 & 1 & 1 & & 93.7 & 1 & 1 & \\
\hline & & 500 & 8 & 1 & 93.4 & 2 & & & 92.8 & 2 & & \\
\hline & 2000 & 500 & 6 & 0.5 & 94.9 & 1 & 1 & & 94.2 & 1 & 1 & \\
\hline & & 500 & 6 & 1 & 93.6 & 2 & & & 93.2 & 2 & & \\
\hline \multirow[t]{5}{*}{$50 \leq \mathrm{CL}_{\mathrm{CR}}<70$} & 1000 & 500 & 12 & 0.5 & 85.4 & 1 & 3 & $A \& 1$ & 70.6 & 1 & 3 & $A \& I$ \\
\hline & 1500 & 500 & 8 & 0.5 & 90.5 & 1 & 2 & & 83.1 & 1 & 2 & \\
\hline & & 500 & 8 & 1 & 85.0 & 2 & & & 75.0 & 2 & & \\
\hline & 2000 & 500 & 6 & 0.5 & 92.0 & 1 & 1 & & 88.2 & 1 & 1 & \\
\hline & & 500 & 6 & 1 & 88.7 & 2 & & & 81.3 & 2 & & \\
\hline \multirow[t]{16}{*}{$\mathrm{CL}_{\mathrm{CR}} \geq 70$} & 750 & 250 & 8 & 0.5 & 78.2 & 1 & 4 & A & 65.4 & 1 & 4 & A \\
\hline & 1000 & 250 & 6 & 0.5 & 83.8 & 1 & 3 & & 73.5 & 1 & 3 & \\
\hline & & 250 & 6 & 1 & 76.4 & 3 & & & 67.6 & 2 & & \\
\hline & & 500 & 12 & 0.5 & 79.1 & 2 & & & 61.0 & 3 & & \\
\hline & 1500 & 250 & 4 & 0.5 & 89.0 & 1 & 2 & & 81.8 & 1 & 2 & 1 \\
\hline & & 250 & 4 & 1 & 81.2 & 2 & & & 74.8 & 2 & & \\
\hline & & 250 & 4 & 3 & 69.7 & 3 & & & 62.4 & 4 & & \\
\hline & & 500 & 8 & 0.5 & 89.4 & 1 & 2 & I & 76.1 & 2 & & \\
\hline & & 500 & 8 & 1 & 80.7 & 2 & & & 68.8 & 3 & & \\
\hline & 2000 & 250 & 3 & 0.5 & 91.0 & 2 & & & 86.7 & 1 & & \\
\hline & & 250 & 3 & 1 & 83.9 & 4 & & & 78.5 & 3 & & \\
\hline & & 250 & 3 & 3 & 71.5 & 6 & & & 67.1 & 5 & & \\
\hline & & 500 & 6 & 0.5 & 92.3 & 1 & 1 & & 84.3 & 2 & 1 & \\
\hline & & 500 & 6 & 1 & 86.1 & 3 & & & 75.0 & 4 & & \\
\hline & & 500 & 6 & 3 & 72.1 & 6 & & & 64.9 & 6 & & \\
\hline & & 1000 & 12 & 0.5 & 85.7 & 3 & & & 67.2 & 5 & & \\
\hline
\end{tabular}

The integrated frequency rate (IFR) was calculated by Monte Calro simulation.

The target microorganism : $P$. aeruginosa

The Chi square test was used to compare the integrated frequency rate of $\% \mathrm{~T}>\mathrm{MIC}$. $\mathrm{P}<0.01$ was deemed significant.

a) : The order was acquired according to the results of comparing the IFR of $\% \mathrm{~T}>\mathrm{MIC}$ among dose regimens in each daily dose.

b) : The order was acquired according to the results of comparing the IFR of \% T $>$ MIC among daily doses in each renal function group.

a), b) : The pair in which significant difference was not recognized was defined as coordinate.

c) : The mark $A$ and I mean alternative regimens and improved regimens, respectively.

CLCR : creatinine clearance

concentrations immediately following drip infusion were $29.7 \mathrm{~g} / \mathrm{mL}$ on $0.5 \mathrm{~h}$-infusion and $8.91 \mathrm{~g} / \mathrm{mL}$ on $4 \mathrm{~h}$ infusion $^{36)}$. These results are congruent with the theory above. However, the \% $>$ MIC on $4 \mathrm{~h}$-infusion was higher than on $1 \mathrm{~h}$-infusion. In his study, The MIC of MEPM against $P$. aeruginosa used to calculate $\% \mathrm{~T}>\mathrm{MIC}$ was a value of an actual detected pathogen $: 4 \mu \mathrm{g} / \mathrm{mL}$. Thus, the calculation method of his study was not the MCS method. The MCS method can calculate the \% T > MIC involving the distribution of MIC. Besides, the MIC value using this study showed that $41.6 \%$ of samples were MIC $>1 \mu \mathrm{g} / \mathrm{mL}$ and $26.6 \%$ of samples were MIC $>4 \mu \mathrm{g} / \mathrm{mL}$. We consider that these samples of high MIC influenced results of the MCS and make a difference in the results of comparisons of infusion times. In the other studies ${ }^{18,35}$, the MIC of MEPM against $P$. aeruginosa used to calculate $\% \mathrm{~T}>\mathrm{MIC}$ were less than our study. On the other hand, in the prestigious study by Kuti et $\mathrm{al}^{28)}$, the distribution of MICs used to calculate 
Table 4 . Summary of the effect of alternative regimens and improved regimens

\begin{tabular}{|c|c|c|c|c|c|c|c|c|c|c|c|c|}
\hline \multicolumn{5}{|c|}{ Actual regimens } & \multicolumn{4}{|c|}{ Alternative regimen } & \multicolumn{4}{|c|}{ Improved regimen } \\
\hline \multirow{2}{*}{$\begin{array}{l}\text { Renal function } \\
(\mathrm{mL} / \mathrm{min})\end{array}$} & \multirow[t]{2}{*}{$\mathrm{n}$} & \multicolumn{2}{|c|}{ The average IFR(\%) } & \multirow{2}{*}{$\begin{array}{l}\text { Totals of daily } \\
\text { doses (mg (a) }\end{array}$} & \multicolumn{2}{|c|}{$\operatorname{IFR}(\%)$} & \multirow{2}{*}{$\begin{array}{l}\text { Totals of daily } \\
\text { doses (mg) }{ }^{(b)}\end{array}$} & \multirow{2}{*}{$\begin{array}{l}\text { Reduction } \\
\operatorname{rate}(\%)^{(c)}\end{array}$} & \multicolumn{2}{|c|}{ IFR( \% ) } & \multicolumn{2}{|c|}{$p$ V alue ${ }^{(d)}$} \\
\hline & & $\% \mathrm{~T}>\mathrm{MIC}=30$ & $\% \mathrm{~T}>\mathrm{MIC}=50$ & & $\% \mathrm{~T}>\mathrm{MIC}=30$ & $\% \mathrm{~T}>\mathrm{MIC}=50$ & & & $\% \mathrm{~T}>\mathrm{MIC}=30$ & $\% \mathrm{~T}>\mathrm{MIC}=50$ & $\% \mathrm{~T}>\mathrm{MIC}=30$ & $\% \mathrm{~T}>\mathrm{MIC}=50$ \\
\hline $\mathrm{CL}_{\mathrm{CR}}<30$ & 91 & $95.0 \pm 1.0$ & $93.9 \pm 1.4$ & 72750 & 96.0 & 94.3 & 45500 & 37.5 & 96.0 & 94.3 & $p<0.01$ & NS \\
\hline $30<\mathrm{CL}_{\mathrm{CR}}<50$ & 39 & $92.7 \pm 1.4$ & $90.2+4.4$ & 43000 & 93.0 & 90.8 & 39000 & 9.3 & 93.8 & 92.6 & $p<0.01$ & NS \\
\hline $50 \leq \mathrm{CL}_{\mathrm{CR}}<70$ & 33 & $80.7 \pm 6.2$ & $67.2+9.8$ & 38500 & 85.4 & 70.6 & 33000 & 14.3 & 85.4 & 70.6 & $p<0.01$ & NS \\
\hline$\overline{C L}_{C R} \geq 70$ & 136 & $77.6 \pm 9.0$ & $59.8 \pm 15.8$ & 237000 & 78.2 & 65.4 & 102000 & 57.0 & 89.4 & 81.8 & $p<0.01$ & $p<0.01$ \\
\hline total & 299 & $85.2+10.3$ & $74.9 \pm 19.4$ & 391250 & 88.1 & 80.3 & 219500 & 43.9 & 91.1 & 84.8 & $p<0.01$ & $p<0.01$ \\
\hline
\end{tabular}

The creatinine clearance of patiens were calculated using the Cockcroft-Gault equation.

The integrated frequency rate (IFR) of $\% \mathrm{~T}>\mathrm{MIC}$ values of 30 and 50 of patients were extrapolated the results of the Monte Carlo simulation on same renal function group and same regimens as actual.

c)The reduction rate was calculated by $((\mathrm{b})-(\mathrm{a})) /(\mathrm{a})$.

d) The two-tailed Mann-Whitney $\mathrm{U}$-test was used to compare the integrated frequency rate between actual regimens and recomended regimens. $\mathrm{P}<0.01$ was deemed significant.

CLCR : creatinine clearance. NS : no significant

was similar to ours. However, their regimens selected for comparison were $1000 \mathrm{mg}$ per $8 \mathrm{~h}$ and $2000 \mathrm{mg}$ per $8 \mathrm{~h}$ and these doses were higher than ours, within a range $250 \mathrm{mg}$ to $1000 \mathrm{mg}$ as the daily dose. With the same infusion time, the higher dose achieves a higher maximum drug concentration and reaches the maximum drug concentration faster ${ }^{38}$. Therefore, the length of time above the MIC on the high dose regimens is not influenced so much by an increase in the drug concentration during infusion time. $\mathrm{Li}$ et al developed an MEPM population pharmacokinetic model using pa tient data and used it to compare the \%T > MIC among regimens with variant infusion times ${ }^{37)}$. They researched the IFR of \%T > MIC at several MIC values. The results lead us to conclude that prolonged infusion improves the attainment rate of the \% $>$ MIC. However, in their study, regimens used for comparison were $1000 \mathrm{mg}$ per $8 \mathrm{~h}$ and were higher doses than our regimens considering the combination of dose and frequency of administration. Therefore, these results suggest that the dose of our selected regimens in the current study is not enough to keep concentration above the MIC against a decrease during $3 \mathrm{~h}$-infusion. However, these regimens were selected according to the instructions printed on the package insert in Japan. Thus, the results of this study show that using these instructions, the view that longer infusion time increases the IFR of $\% \mathrm{~T}>\mathrm{MIC}$ is unsupportable. That value is influenced by the distribution of MICs. In the situation of low daily dose or low dosage and high rate of resistance, the possibility that the longer infusi on time may decrease the IFR of \% $>$ > MIC should be considered. In the other hand, the results show that shorter dose interval and higher daily dose improve the IFR of \%T > MIC. Results are congruent with several reports ${ }^{35}$.

Secondly, the recommended regimen from the results of the MCS makes it possible to decrease the consumption of MEPM while keeping the IFR of \%T > MIC. Because the improved regimens of this study increase the IFR significantly, the MCS method is suited for defined regimens to increase the effectiveness of antibiotics. In addition, it is ex- pected that the recommended regimen based on MCS enables shortening of the duration of administration.

The limitation of our study is that change in the clinical effect was not compared between the actual regimen use and the recommended regimen use. However, the relationship between \% $>$ MIC and the clinical effect is under intense study ${ }^{18,28,35,37,38)}$ and the effectiveness of the increase \% $\mathrm{T}>$ MIC has reached a consensus ${ }^{23-31}$. More studies concerning the total dose during administration term are needed to confirm the inhibitory effect of consumption of antibiotics using the MCS method. In this study, the rate of patients whose $\mathrm{CL}_{\mathrm{CR}}<70$ was over $50 \%$. Thus, an accumulation-related problem may be concerned. However, the $C L$ value of the patient was included in the calculating formula of $\% \mathrm{~T}>$ MIC in this study. Moreover, it is reported that the bioaccumulation potential of meropenem is low ${ }^{32}$.

In conclusion, this study demonstrates that the recommended regimen used by the MCS makes it possible to de crease the consumption of MEPM. The results of this study warn that the blind choice of the prolonged infusion causes the rise in the IFR of \% T > MIC to be uncertain. By selection of the appropriate dosage depending on the MIC of the pathogen, the rise in the IFR can be accurately gauged and administered.

Acknowledgements We thank Mr. Manago, director of the central clinical laboratory at lizuka hospital for donating the Microbiology data, Mr. Oda and Mr. Cotton for technical assis tance.

\section{References}

1) A meropen special investigation (national sensitivity investigation) meeting for the study, Nationwide surveillance of parenteral antibiotics containing meropenem activities against clinically isolated strains in 2004, The Jpn.J. Antibiotics, 58, 655-689 (2005).

2) S. Kohno, A. Watanabe, T. Matsushima, HAP study 
Group, Nationwide multicenter survey on the pathophysiology of hospital-acquired pneumonia and the use of first-line antibiotics in Japan, Jpn. J. Chemother., 54, 453-464 (2006).

3) The committee for the JRS guidelines in the manage ment of respiratory infections ", The JRS Guidelines for the Management of Community-acquired Pneumonia in A dult", ed. by The committee for the JRS guidelines in management of respiratory infections, The Japanese Respiratory Society, Tokyo, 2002, pp. 39-85.

4) D.N. Gilbert, R.C. Moellering Jr., G.M. Eliopoulos, M. A. Sande," The Sanford Guide to A ntimicrobial Therapy", 37th, A ntimicrobial therapy Inc., V irginia, 2007, pp.4-60.

5) S. Y oshimoto, S. Okauchi, K. Kanatani, Epidemiological study and control of the outbreak of urinary tract infection by multi-drug-resistant Pseudomonas aeruginosa, Environmental Infections, 20, 37-43 (2005).

6) K. Senda, Y. A rakawa, K. Nakashima, H. Ito, S. Ichiyama, K. Shimokata, M. Ohta, Multifocal outbreaks of metallo-betalactamase producing Pseudonomas aeruginosa resitant to broad-spectrum betalactams, including carbapenems, Antimicrob. Agents Chemother., 40, 349353 (1996).

7) X.Z. Li, D.M. Livermore, H. Nilaido, Role of efflux pu$\mathrm{mp}(\mathrm{s})$ in intrinsic resistance of Pseudomonas aeruginosa : resistance to tetracycline, chloramphenicol and norfloxacin, Antimicrob. Agents Chemother., 38, 17321741 (1994).

8) I. Kobayashi, M. Hasegawa, M. Nishida, Alteration of serotype and drug susceptibility of some Pseudomonas aeruginosa isolates by exposure to human serum and polymorphonuclear leukocytes, Kansenshogaku Zasshi, 68, 500-507 (1994).

9) O. Lomovskaya, M.S. Warren, A. Lee, J. Galazo, R. Fronko, M. Lee, J. Blais, D. Cho, S. Chamberland, T. Renau, R. Leger, S. Hecker, W. Watkins, K. Hoshino, H. Ishida, V.J. Lee, Identification and characterization of inhibitors of multidrug resistance efflux pumps in Pseudomonas aeruginosa: novel agents for combina tion therapy, Antimicrob. Agents Chemother., 45, 105116 (2001).

10) P. Nordmann, M. Guibert, Extended-spectrum $\beta$-lacta mases in Pseudomonas aeruginosa, J. Antimicrob. Chemother., 42, 128-131 (1998).

11) R.M. Shawar, D.L. MacLeod, R.L. Garber, J.L. Burns, J.R. Stapp, C.R. Clausen, S.K. Tanaka, A ctivities of tobramycin and six other antibiotics against Pseudomonas aeruginosa isolates from patients with cystic fibrosis, Antimicrob. Agents Chemother., 43, 2877-2880 (1999).

12) A. Tsuji, I. Kobayashi, T. Oguri, M. Inoue, E. Y abuuchi, S. Goto, The Pseudomonas aeruginosa Epidemiological Research Group, An epidemiological study of the susceptibility and frequency of multilpledrugresistant strains of Pseudomonas aeruginisa isolated at medical institutes nationwide in Japan, J. Infect. Che- mother., 11, 64-70 (2005).

13) P. Toltzis, T. Y amashita, L. V ilt, M. Green, A. Morris sey, S. Spinner-Block, J. Blumer, A ntibiotic restriction does not alter endemic colonization with resistant Gram-negative rods in a pediatric intensive care unit, Crit. Care. Med., 26, 1893-1899 (1998).

14) J. Quale, D. Landman, G. Saurina, E. A twood, V. DiTore, K. Patel, Manipulation of a hospital antimicrobial formulary to control an outbreak of vancomycinresistant Enterococci, Clin. Infect. Dis., 23, 1020-1025 (1996).

15) I.M. Gould, B. Jappy, Trends in hospital antibiotics prescribing after introduction of an antibiotic policy, $J$. Antimicrob. Chemother., 38, 895-904 (1996).

16) Y. Fujita, Y. Yamasaki, Clinical evaluation of our guideline for use of the specific antibacterial agents, Environmental Infections., 20, 31-36 (2005).

17) Y. Ogasawara, K. Y ashima, S. Kondou, T. Harino, T. Odaki, N. Nagasaki, M. Mitao, Usefulness of the TDM utilization system on the proper use of the antibiotics for MRSA, Environmental Infections, 18, 323-328 (2003).

18) G.L. Drusano, Prevention of Resistance: A goal for dose selection for antimicrobial agents, Clin. Infect. Dis., 36, 42-50 (2003).

19) T. Muro, R. Hideshima, K. Nakamura, H. Kamimura, Effort to promote proper use of anti methicillin-resistant Staphylococcus aureus agents and carbapenems, Jpn. J. Chemother., 54, 511-519 (2006).

20) J.D. Turnidge, The pharmacodynamics of $\beta$-Lactams, Clin. Infect. Dis., 27, 10-22 (1998).

21) W.A. Craig, The role of pharmacodynamics in effective treatment of community-acquired pathogens, Advanced Studies in Medicine, 2, 126-133 (2002).

22) W.A. Craig, Pharmacokinetic/pharmacodynamic parameters: Rationale for antibacterial dosing of mice and men, Clin. Infect. Dis., 26, 1-12 (1998).

23) J.M. Ellis, J.L. Kuti, D.P. Nicolau, Use of Monte Carlo simulation to assess the pharmacodynamics of $\beta$ Lactams against Pseudomonas aeruginosa infection in children: A report from the OPTAMA program, Clin. Ther., 27, 1820-1830 (2005).

24) R.N. Jones, J.T. Kirby, M.L. Beach, D.J. Biedenbach, M.A. Pfaller, Geographic variations in activity of broad-spectrum $\beta$-lactams against Pseudomonas aeruginosa : summary of the worldwide SENTRY A ntimicrobial Surveillance Program (1997-2000), Diagn. Micr. Infec. Dis., 43, 239-243 (2002).

25) J.L. Kuti, C.H. Nightingale, D.P. Nicolau, Optimizing pharmacodynamic target attainment using the MY STIC A ntibiogram : Data collected in North A merica in 2002, Antimicrob. Agents. Chemother., 48, 2464-2470 (2004).

26) R.G. Masterton, J.L. Kuti, P.J. Turner, D.P. Nicollau, The OPTAMA programme: utilizing MYSTIC(2002) to predict critical pharmacodynamic target attainment aga 
inst nosocomial pathogens in Europe, J. Antimicrob. Chemother., 55, 71-77 (2005).

27) C.R.V. Kiffer, C. Mendes, J.L. Kuti, D.P. Nicolau, Pha rmacodynamic comparisons of antimicrobials ag-ainst nosocomial isolates of Escherichia coli, Klebsiella pneumoniae, Acinetobacter baumannii and Pseudomonas aeruginosa from the MYSTIC surveillance program: the OPTAMA Program, South America 2002, Diagn. Micr. Infec. Dis., 49, 109-116 (2004).

28) JL. Kuti, PK. Dandekar, CH. Nightingale, DP. Nicolau, Use of Monte Carlo simulation to design an optimized pharmacodynamic dosing strategy for meropenem, $J$. Clin. Pharmacol ., 43, 1116-1123 (2003).

29) D. Maglio, J.L. Kuti, D.P. Nicolau, Simulation of antibiotic pharmacodynamic exposure for the empiric treatment of nosocomial bloodstream infections: A report from the OPTAMA program, Clin. Ther., 27, 10321042 (2005)

30) J.L. Kuti, C. Ong, M. Lo, D. Melnick, N. Soto, D.P. Nicolau, Comparison of probability of target attainment calculated by Monte Carlo simulation with meropenem clinical and microbiological response for the treatment of complicated skin and skin structure infections, Int. J. Antimicrob. Agents, 28, 62-68 (2006).

31) J.S. Bradley, M.N. Dudley, G.L. Drusano, Predicting efficacy of antiinfective with pharmacodynamics and Monte Carlo simulation, Pediatr. Infect. Dis., 22, 982992 (2003).
32) M. Nakashima, T. Uematsu, M. Kanamaru, Clinical phase one study of meropenem, chemotherapy, 40, 258275 (1992).

33) M. Chimata, M. Nagase, Y. Suzuki, M. Shimomura, S. Kakuta, Pharmacokinetics of meropenem in patients with various degrees of renal function, including pa tients with end-stage renal disease, Antimicrob. Agents Chemother., 37, 229-233 (1993).

34) " Interview form of meropen for intravenous drip infusion", Dainippon Sumitomo Pharma Co., Ltd., 2005, p.25.

35) H.M. Mattoes, J.L. Kuti, G.L. Drusano, D.P. Nicolau, Optimizing antimicrobial pharmacodynamics: Dosage strategies for meropenem, Clin. Ther., 26, 1187-1198 (2004).

36) H. Mikamo, Optimizing meropenem therapy based on pharmacokinetics/pharmacodynamics (PK/PD) for severe infectious disease, Antibiot. Chemother., 21, 405413 (2005).

37) J.W. Mouton, J.N. van den Anker, Meropenem clinical pharmacokinetics, Clin. Pharmacokin., 28, 275-286 (1995).

38) C. Li, J.L. Kuti, C.H. Nightingale, D.P. Nicolau, Populatin Pharmacokinetic Analysis and Dosing Regimen Optimization of Meropenem in Adult Patients, J. Clin. Pharmacol ., 46, 1171-1178 (2006). 